\section{A estética do grotesco e a produção audiovisual para a educação em saúde: segregação ou empatia? O caso das leishmanioses no Brasil}

\author{
Aesthetics of the grotesque and audiovisual \\ production for health education: segregation or \\ empathy? The case of leishmaniasis in Brazil
}

\footnotetext{
${ }^{1}$ Centro de Pesquisas René Rachou, Fundação Oswaldo Cruz,

Belo Horizonte, Brasil. 2 Université Michel de Montaigne Bordeaux 3 Bordeaux, France.

Correspondência D. N. Pimenta Laboratório de Educação em Saúde, Centro de Pesquisas René Rachou, Fundação Oswaldo Cruz.

Av. Augusto de Lima 1715, Belo Horizonte, $M G$ 30190-002, Brasil. nacif@cpqrr.fiocruz.br
}

\begin{abstract}
In order to understand audiovisual production on health and disease and the pedagogical effects of health education mediated by educational videos, this article analyzes the audiovisual production on leishmaniasis in Brazil. Fourteen educational videos showed the hegemony of TV aesthetics, particularly a journalistic paradigm with constant use of voice-over, inducing the fixation of meanings. Rather than stimulating critical reflection on the social circumstances of leishmaniasis, the videos' discourse and images promote a banal, noncritical, stigmatized representation of the disease. Individuals with the disease are subjected to visual exposure rather than being involved critically and sensitively as protagonists in prevention and treatment. The article thus presents approaches based on studies of visual and health anthropology, arguing in favor of an innovative approach to the production and utilization of educational videos in health education, mediated through audiovisuals. Health education should respect and engage in dialogue with various cultures, subjectivity, and citizenship, developing an audiovisual aesthetics (in terms of narrative and image) that fosters an educational praxis in the field of collective health.
\end{abstract}

Leishmaniasis; Health Education; Anthropology
Denise Nacif Pimenta 1

Anita Leandro 2

Virgínia Torres Schall 1

\section{Introdução}

A produção audiovisual sobre as leishmanioses não tem dado conta de uma representação problematizada da doença, entendendo-a, no contexto de suas relações sócio-culturais. Os vídeos distribuídos no Brasil oscilam entre o discurso técnico-científico e o estilo televisivo-espetacular, com preponderância de uma "estética do grotesco" 1 .

$\mathrm{Na}$ análise de materiais educativos impressos sobre as leishmanioses, Luz et al. 2 avaliam as representações gráficas das leishmanioses. Os resultados dessa pesquisa alertaram para um processo de imposição de discursos e reprodução de preconceitos através de desenhos e fotografias. Ampliando este universo de investigação, questiona-se sobre a participação das imagens em movimento na constituição de toda uma cultura visual em torno da doença. Assim, trazemos o debate para o campo da antropologia visual, da saúde e dos estudos cinematográficos. Analisam-se vídeos educativos sobre as leishmanioses distribuídos no Brasil com intuito de compreender a produção da imagem cultural da doença e do corpo do portador de leishmaniose presente nesses materiais audiovisuais. A partir da análise crítica destes materiais, abordaremos algumas proposições metodológicas para uma representação audiovisual diferenciada da doença. 


\section{Saúde e imagem: encontros na antropologia}

Com relação aos vídeos educativos sobre leishmaniose no Brasil, seja nos contextos dos serviços de saúde ou nas áreas de educação e comunicação, segundo Pimenta ${ }^{3}$ e Pimenta et al. ${ }^{4}$ a escassez e a baixa qualidade destes nos remete à necessidade de uma reflexão crítica em torno dessa produção audiovisual e sobre a possibilidade de propor novas abordagens do vídeo nesse campo da saúde. Estudos interdisciplinares podem contribuir para a compreensão da doença em diversos campos da saúde coletiva, e a antropologia da saúde e antropologia visual podem auxiliar numa maior compreensão a respeito da produção audiovisual sobre as leishmanioses 3,4.

Noções como saúde e doença referem-se a fenômenos complexos que conjugam fatores biológicos, sociais, econômicos, ambientais e culturais. A complexidade do objeto, assim definido, transparece na multiplicação de discursos sobre saúde que coexistem atualmente, privilegiando diferentes fatores e metodologias, construindo, cada qual, seu próprio discurso. A antropologia tem apontado os limites e insuficiências da tecnologia biomédica quando se trata de alterar o estado da saúde de uma população. Ela nos revela que este estado tem estreita ligação com o modo de vida das populações e seu universo social e cultural 5. Como lembra White 6 (p. 51): “O papel da antropologia seria restituir aos fenômenos biológicos sua verdadeira natureza social, desconstruindo a indevida 'naturalização' empreendida pela ciência".

Assim, conjugando debates sobre o corpo e a imagem com aportes teórico-metodológicos da antropologia, pode-se levantar a seguinte questão: como pensar o corpo e suas imagens? Segundo Maylysse 7, a antropologia visual auxilia-nos com metodologias multidisciplinares que inventariam as lógicas sociais e culturais que se encontram na corporalidade humana, pois o corpo apresenta-se como um espelho do social. Se o corpo é um "espelho social", como interpretar suas imagens? Como pensar as relações contextuais que se estabelecem entre o visual, o corporal e o cultural?

Todas as culturas, através dos tempos, sempre se permearam por usos distintos da imagem, sejam mentalmente abstratas - baseadas em relatos orais ou em outras experiências perceptivas -, sejam visualmente concretas - baseadas em suportes materiais. Segundo Aumont 8, a imagem é classificada em três modos: $o$ modo simbólico através de símbolos e ícones sagrados que acompanham conceitos de idéias; $o$ modo epistêmico no qual a imagem é fonte de informação visual de uma época, sociedade, hábitos; e o modo estético no qual a imagem é criada com o intuito de agradar ao telespectador de forma a provocar sensações e sentimentos. Assim, a imagem como representação cultural, seja ela no seu modo simbólico, epistêmico ou estético, é uma construção de conhecimento da realidade 8

A ciência da medicina e a ciência da imagem se encontram em certo período histórico, que se estende aos dias de hoje, onde certo "positivismo da imagem" impera. Tanto a medicina como o cinema, desde suas origens, basearam seus pressupostos no "real". Bernardet 9 (p. 58) lembra que "a história do cinema é em grande parte a luta constante para manter ocultos os aspectos artificiais do cinema e para sustentar a impressão da realidade". Ambos os conceitos de imagem e saúde, respectivamente no campo do cinema e da medicina, têm sido objeto de críticas e reformulações frente aos seus pressupostos "positivistas". Percebe-se a tendência positivista da medicina de utilização das imagens, como a primazia absoluta do empirismo, naturalização e objetividade do discurso médico. Estes fatos evidenciam relações complexas entre ciência e espetáculo, onde a forma de conhecimento científico se dá principalmente pelo que Pinto 10 denomina de "ocularcentrismo". Assim, "a importância das imagens na prática médica atingiu tal ponto que, mesmo quando o paciente está realmente presente, a análise dos exames de imagem possui mais valor que os dados do exame clínico ou anamnese. Tal fato acaba por inverter a função da imagem, que em princípio, consiste em trazer à presença algo ausente, fazendo com que ela acabe por afastar ou abafar algo existente e presente" 10 (p. 43).

Portanto, a questão da representação do “real”, enquanto legitimação da "verdade", tanto no campo da saúde coletiva como na mídia como um todo, tem sido questionada ao longo da história, porém ainda se configura como pressuposto hegemônico da sociedade moderna. Jean-Luc Godard 11 (p. 32) critica esse modelo hegemônico, ao dizer que "não se trata de uma imagem justa. (...) É justo uma imagem”. A imagem não remete à coisa em si, mas à imagem do objeto.

Essa questão com a qual, ambos, antropologia e cinema se deparam, lida, em última instância, com questões mais amplas sobre a representação do real. Como representar o portador de leishmaniose? Como construir imagens em movimento que não reduzam a alteridade e as especificidades deste portador? André Parente 12 (p. 51) coloca esta questão nos seguintes termos: “... a linguagem, seja no cinema, seja na antropologia, é uma questão de método: como mostrar o outro sem o reduzir a um objeto, ou melhor, como mostrar o outro preservando aquilo que ele tem de 
mais interessante: a sua diferença, a sua radical alteridade?".

No que se refere à antropologia visual, seu impulso no Brasil se deu a partir dos anos 90 do século passado, sendo campo ainda em consolidação. A utilização das imagens dentro desta disciplina quer como objeto, quer como meio na pesquisa social, requer rigor conceitual. Aliás, a ausência de aparato teórico aprofundado e abrangente de apropriação do audiovisual em contextos educativos e etnológicos tem aparecido na literatura como constante ponto de problematização 13,14,15,16.

Com esse novo arcabouço teórico-metodológico, descobriu-se que a antropologia visual poderia permitir descrever e compreender ordens e fatos dificilmente traduzidos pela palavra. Para Samain \& Sôlha 14 (p. 6), essa nova abordagem pode "abrir espaço para uma vertente experimental, consciente de um 'novo fazer' gerando subsídios necessários à elaboração de metodologias específicas do uso dos multimeios nesse campo".

Portanto, a antropologia visual, aliada à antropologia da saúde podem juntas rever o estatuto da imagem e devolver a "carne e osso" ao corpo humano e social. A antropologia visual pode nos auxiliar a fazer frente à nossa "cegueira cultural" integrante de disciplinas com base na escrita, estando atentos a símbolos, sinais e qualquer forma de comunicação cultural, especialmente nos tempos de hoje, quando nossas mentes navegam num mundo de imagens sempre em expansão. A antropologia visual abre canais para meios de expressões que, desconhecendo fronteiras, reduzem distâncias e abolem preconceitos, abrindo janelas privilegiadas para infinitos jogos de prismas, mitos e memórias que perigosamente são chamados de realidade. Assim, é preciso, como diria Artaud 17 (p. 153) "navegar, sem naufragar, no território dos outros”.

\section{As leishmanioses na história}

As leishmanioses constituem importante grupo de doenças parasitárias que afligem a humanidade há vários séculos, sendo que, somente em 1903, W. B. Leishman descreveu os corpúsculos que hoje se reconhecem como Leishmania 18.

Nos seres humanos, a leishmaniose pode se manifestar, dependendo da espécie do parasita, de duas formas: tegumentar e visceral. $\mathrm{Na}$ leishmaniose tegumentar ou leishmaniose tegumentar americana, a doença se manifesta principalmente por lesões na pele. Uma variedade da leishmaniose tegumentar, a leishmaniose muco-cutânea, origina lesões também destrutivas e desfigurantes, atingindo regiões mucosas do corpo, como a parte nasal, oral e faringe. Já na leishmaniose visceral ou calazar, as regiões do corpo mais afetadas são as vísceras, e seus sintomas são caracterizados por febre alta, irregular e prolongada, perda de peso, aumento do fígado, dentre outros, podendo causar morte se não tratada corretamente 18,19 .

No Brasil, o principal vetor da leishmaniose são insetos flebotomíneos do gênero Lutzomyia (popularmente conhecido como "mosquito palha”, "cangalhinha”, entre outros), tendo os cães como seu principal reservatório doméstico, propiciando um crescente número de casos de leishmaniose nos grandes centros urbanos 20 . De acordo com a Organização Mundial da Saúde (OMS) 19, no Brasil, as leishmanioses constituem grave problema de saúde pública, sendo a leishmaniose tegumentar americana diagnosticada em praticamente todos os Estados brasileiros e a leishmaniose visceral, notificada em 17 Estados, atingindo quatro das cinco regiões geográficas do país.

Apesar de a doença ser registrada há vários séculos, os conhecimentos científicos sobre as inserções sociais são escassos. Conforme Graham 21, mesmo na área biomédica, somente em 1976 é que a OMS incluiu as leishmanioses como um dos seis itens no Programa Especial de Pesquisa e Treinamento em Doenças Tropicais (TDR). As leishmanioses constituem infecções longas e progressivas, distintas das doenças fatais que matam rapidamente. A leishmaniose tegumentar americana, por exemplo, é caracterizada por alta taxa de morbidade em vez de mortalidade. Porém, desconsiderá-la é menosprezar o grande sofrimento humano, sem falar nos custos sociais e econômicos para os países afetados pela doença.

\section{Metodologia e procedimentos de análises}

Calcados no estudo O Império do Grotesco, Sodré \& Paiva ${ }^{1}$ analisam a estética do grotesco no começo do novo milênio, não só nas artes, mas na mídia como um todo. A categoria do grotesco pode auxiliar na compreensão da produção, representação e utilização das imagens não só na saúde coletiva como um todo, mais especificamente, nos vídeos educativos sobre as leishmanioses. Vanoye \& Goliot-Lété 22 (p. 23) afirmam que "analisar um filme é também situá-lo num contexto, numa história. E, se consideramos o cinema como arte, é situar o filme numa história das formas fílmicas".

Apesar de quase meio século de discussão sobre o audiovisual pela antropologia, sem falar na própria teoria cinematográfica, que vem pensan- 
do o estatuto das imagens por mais de um século, na prática, o que se constata é ainda uma apropriação desproblematizada das imagens em contextos como o da educação e da saúde coletiva.

Neste artigo, foram analisados 14 vídeos educativos e institucionais sobre as leishmanioses, distribuídos no Brasil a partir da antropologia visual e da saúde (Tabela 1). Esses vídeos foram decupados e analisados por seqüência, tanto do ponto de vista do conteúdo narrativo, ou seja, dos discursos elaborados, quanto do ponto de vista da forma.

\section{Resultados}

No começo do novo milênio, torna-se cada vez mais evidente que o grotesco é algo recorrente não apenas nas artes, como também na vida contemporânea, sem que se registrem estudos compreensivos sobre o fenômeno. Com exceção de estudos clássicos de Bakhtin 23 e Kayser 24, existem poucos trabalhos voltados para o estudo do grotesco. Sodré \& Paiva 1 trabalham o tema especificamente na mídia e na televisão.

A palavra "grotesco" vem de gruta, porão (grotta em italiano). No século XIX o grotesco é apresentado como categoria estética e Victor
Hugo 25, em seu prefácio a Cromwell, é o primeiro a se apresentar como porta-voz do Romantismo no tocante ao interesse pelo cômico e pelo estranho, presentes em antigas formas populares de diversão e de sarcasmo. Como assinala Bakhtin 23, agora prestes a ingressarem no domí-nio da estética culta. De acordo com Sodré \& Paiva 1 (p. 62), “a equação mais simples deste fenômeno esteticamente apontado como 'grotesco' será: Grotesco = Homem \# Animal + Riso (...) Pode-se rir do terrivel ou das desproporções escandalosas das formas, transformando-as em veículos de irrisão e de provocação aos cânones do esteticamente correto. Esta possibilidade tem garantido a permanência do grotesco na História, assim como sua recorrência na vida, nas artes e na mídia contemporânea".

Verificamos nos vídeos analisados uma forte estética televisiva e grotesca. A narrativa segue o padrão clássico, com histórias contadas com princípio, meio e fim. Os planos, em geral, são curtos e intercalados por músicas e voz em off. A voz em off é amplamente utilizada, ditando o sentido do que está sendo apresentado, o que não acontece sem implicações ideológicas importantes.

Com relação ao conteúdo, a estética do grotesco impera nos materiais analisados. Uma

Vídeos sobre leishmanioses distribuídos no Brasil

\begin{tabular}{|c|c|c|c|}
\hline Instituição & Título do vídeo & Data & Duração (minutos) \\
\hline Departamento de Parasitologia, Instituto de Biologia, & Leishmaniose Tegumentar & 1981 & 10 \\
\hline Universidade Estadual de Campinas/Laboratório & Leishmaniose Tegumentar Americana & 1983 & 21 \\
\hline \multirow[t]{3}{*}{ Interdisciplinar para a Melhoria da Comunicação } & e Leishmaniose Visceral & 1983 & 48 \\
\hline & Leishmaniose & & \\
\hline & Diagnóstico Laboratorial & 1995 & 38 \\
\hline \multirow[t]{2}{*}{ Globo Vídeo } & Sanitarismo & 1986 & 22 \\
\hline & Mosquitos & 1986 & 28 \\
\hline TVE (Mato Grosso do Sul) & Dermatologia & 1992 & 17 \\
\hline Studios Design Filmagens e Produções/Programa de & Projeto de Controle de & 1992 & 19 \\
\hline Controle de Doenças Endêmicas do Nordeste. & Doenças Endêmicas no & & \\
\hline Fundação Nacional de Saúde & Nordeste - PCDEN & & \\
\hline \multirow[t]{2}{*}{ Empresa Brasileira de Pesquisa Agropecuária } & Os Benefícios da Biotecnologia & 1994 & 20 \\
\hline & para os Consumidores & & \\
\hline Universidade Federal do Rio Grande do Norte/ & Calazar & 1992 & 9 \\
\hline \multicolumn{4}{|l|}{ Secretaria Municipal de Saúde de Natal } \\
\hline Ministério da Saúde/Fundação Nacional da Saúde & O Controle das Leishmanioses & 1991 & 38 \\
\hline Programa Especial de Pesquisa e Treinamento em & Leishmaniasis: The Slow Killer & 1990 & 18 \\
\hline \multicolumn{4}{|l|}{ Doenças Tropicais/Organização Mundial da Saúde } \\
\hline EMA Vídeos & Leishmaniose & 1993 & 12 \\
\hline Universidade Federal do Pará & Série Academia Amazônia & 1992 & 5 \\
\hline
\end{tabular}


doença endêmica como a leishmaniose tegumentar, com aspectos claramente expostos no corpo, como lesões, feridas, no rosto ou pelo restante do corpo, muito semelhantes à hanseníase, está imbuída de discriminação e representações estereotipadas. A imagem do portador de leishmaniose merece todo o devido cuidado em qualquer tipo de material educativo, especialmente em materiais audiovisuais, pois estes são calcados na imagem. Como em nossa sociedade a imagem em movimento tem o estatuto hegemônico de representar o "real", deve-se manter um cuidado especial ao lidar com imagens sobre as leishmanioses nos materiais audiovisuais, já que esse tipo de representação pode ser confundido pelo próprio "real” 26,27.

A maioria dos materiais educativos ainda utiliza a imagem em movimento como mera ilustração e descrição do "real", sendo as leishmanioses e seu portador meros "objetos" de descrição e ilustração. Eis uma questão crucial para a educação em saúde mediada pelo audiovisual: a imagem não deveria ser colocada a serviço da mera ilustração de conteúdos de cursos ou de pesquisas científicas. De acordo com Leandro 27, essa “pedagogia do transporte", tão antiga quanto nociva, favorece apenas a imposição de discursos alheios às imagens, tanto o discurso puramente pedagógico como o discurso científico. O mundo sensível, que deveria ser revelado pelas imagens visuais e sonoras, acaba submerso.

Assim, os vídeos tendem a oscilar entre "aulas gravadas" e "reportagens jornalísticas". Os discursos da educação e da televisão, em especial do telejornalismo, são simplesmente transportados aos vídeos sem a menor contextualização dos fatores sociais e culturais implicados na transmissão e controle da doença. Consuelo Lins 28 destaca no uso de entrevistas "povo fala", enquetes e depoimentos anônimos pela televisão um mecanismo para se confirmar o real. O texto é seguido de uma entrevista que exemplifica o que acabou de ser dito, reforçando e justificando a informação central. De acordo com Lins 28 (p. 47), essas frases curtas cuidadosamente editadas: “...imprimem a marca do mundo em narrações assépticas que sabem, ou simulam saber, sobre a vida dos entrevistados muito mais do que eles próprios. (...) Essa voz toda poderosa, não apenas descreve o real, mas o interpreta e fixa significações...".

Com essa estética jornalística de "povo fala" os entrevistados são referenciados como "os doentes" e suas falas dão pouca margem à expressão de suas singularidades e experiências.

Todos os vídeos também tendem a reproduzir discursos internos, como se se tratasse de produções dirigidas exclusivamente aos seus próprios realizadores. Nota-se em quatro vídeos que, apesar de serem realizados em épocas diferentes, há repetição das mesmas imagens. Leishmaniose (1983) contém cenas de Leishmaniose Tegumentar Americana e Leishmaniose Visceral (1983) e de Leishmaniose Tegumentar (1981), que por sua vez reutiliza algumas cenas de Diagnóstico Laboratorial (1985).

Schall \& Diniz 29 (p. 37) alertam para essa reutilização a-crítica das imagens, lembrando que "muitos dos materiais informativos sobre doenças produzidos no Brasil têm se configurado como cópias uns dos outros, perpetuando erros há décadas". As informações são apenas "ilustradas" com cenários de salas de aulas, exercícios de fixação do conteúdo, cartelas e quadro negro, dentre outros. Constata-se um exibicionismo da técnica, com a utilização de vários efeitos de montagem que visam à exaltação do discurso científico e pedagógico. Porém, paradoxalmente, com exceção do vídeo O Controle das Leishmanioses (1991), a qualidade técnica da imagem e do som é, geralmente, incompatível com a objetividade do discurso veiculado (imagens fora de foco, som inaudível e repetição do mesmo plano). Tudo isso pode ser observado na série Leishmaniose Tegumentar Americana e Leishmaniose Visceral (1983).

No vídeo Leishmanise Tegumentar (1981), há seqüências onde fotos do vetor, onde lesões e parasitas são ilustradas com uma voz em off que narra o que está sendo mostrado. Percebemos, pela mão na tela apontando para as fotos, que se trata de imagens de um projetor de slides, lembrando um contexto de sala de aula. A voz que narra somente afirma: "isto é um flebótomo [vetor] (...) aqui vemos um amastigota [parasita]...". A imagem é apenas descrita, sem nenhum tipo de contextualização do conteúdo visualizado. É como se os vídeos fossem realizados para um público especializado que detém conhecimentos prévios sobre a doença. Porém, ao mesmo tempo, misturam-se conteúdos simplistas demais para tal público alvo, mesclando assim, num mesmo material, tipos de linguagens técnicas que variam em grau e complexidade, confundindo o espectador. A relação dos materiais educativos com o "público alvo" é outra questão importante na educação em saúde. Como colocam Luz et al. ${ }^{2}$, a maioria dos materiais impressos não explicita o seu público alvo, criando confusões quanto à adequação da linguagem utilizada. Ao mesmo tempo em que se simplificam certas informações, até em excesso em alguns casos, infantilizando e menosprezando o espectador; usam-se jargões técnicos ou classificações científicas, para um público especializado da área biomédica.

O fenômeno da culpabilização da vítima, conforme conceitualizado por Stotz 30 é outro re- 
curso freqüentemente utilizado. Esta culpabilização da vítima se dá ao se individualizar a culpa da doença à população, não discutindo realmente as situações políticas e sociais que geraram essas péssimas condições de saúde e doença. Os materiais audiovisuais analisados utilizam esse discurso freqüente de materiais educativos em saúde. O vídeo Dermatologia (1992) tem uma seqüência bem ilustrativa dessa culpabilização da vítima e isenção da responsabilidade dos profissionais. O vídeo inicia-se com várias imagens de pessoas nas ruas e corta para um ambiente de estúdio jornalístico onde um repórter fala: "Até mesmo a bíblia já expressava o preconceito contra essas doenças de pele e a medicina tem esse preconceito como desafio. (...) O que dificulta é a falta de informação, porque por muitas pessoas desconhecerem a doença, acaba retardando o auxílio que a medicina oferece" (vídeo Dermatologia, 1992).

Nessa frase, fica implícito que a medicina está fazendo a sua parte, portanto cabe ao povo buscar a informação e se tratar corretamente. A isenção da responsabilidade dos profissionais de saúde também se encontra implícita neste vídeo, em que se isentam os profissionais (público a que se destina) de transformar a sua prática, fixando significações aos doentes e aos próprios profissionais.

A fala do povo (geralmente em formato de entrevistas), na montagem e na edição do produto final, é cortada e extremamente curta em sua duração, não expressando as singularidades de cada entrevistado, apenas confirmando a idéia geral do vídeo. Rouch 31 (p. 64) explica essa "maquiagem”, onde há um "tipo de inversão da forma dessas imagens: o cenário torna-se principal interesse em detrimento dos atores metamorfoseados em acessórios secundários".

O cenário da pobreza é enfatizado em detrimento da fala e depoimentos dos portadores, os quais são transformados em meros acessórios. A estética televisiva não realmente "escuta" a fala popular, muito menos dialoga com os entrevistados. Utilizam-se a imagem e a fala do povo apenas para confirmar o que já se tinha como pressuposto, "povo" = "pobreza". Nestas associações, na saúde pública, inclui-se a questão da doença, afirmando-se "povo" = "pobreza" = "doença", confirmando assim, representações estereotipadas. O reforço de representações estereotipadas acaba por inviabilizar os vídeos enquanto possibilidade de informação crítica e reflexiva, capaz de estimular a construção de conhecimentos que possam, de fato, contribuir para os processos de prevenção da doença e promoção da saúde.

O vídeo Projeto de Controle de Doenças Endêmicas no Nordeste (1992) realiza essa equação de forma bastante grotesca. O vídeo inicia-se com a música dos Titãs: O Pulso, em off, com mais ou menos três minutos (duração da música) com imagens de pessoas em situações de extrema pobreza, pessoas andando no lixo, esgotos perto de casas, pessoas doentes chorando e uma criança defecando em plano fechado perto de um esgoto. Essa introdução composta de planos curtíssimos (do estilo clipe), onde pobreza e doença são associadas, dramatiza aspectos do grotesco escatológico da população. Esse vídeo pretendeu discutir as várias doenças endêmicas do Nordeste, como as leishmanioses, esquistossomose e a doença de Chagas, porém as formas nas quais as imagens e os sons são utilizados fazem do contexto da população um espetáculo, aqui no caso, literalmente faz-se um clipe desse sofrimento.

$\mathrm{Na}$ estética do grotesco, o monstruoso destaca-se como o traço mais constante. A palavra monstro deriva da palavra em Latim "monstra", que significa mostrar, avisar ou assinalar, evoluindo para o verbo moderno demonstrar. Assim, o monstro é aquele que se mostra, território de hiper-representação. Thonson 32 faz uma interessante genealogia do "freak discurse" na cultura ocidental moderna. Esse tipo de discurso foi gradualmente sendo apropriado pela ciência (século XIX) com o estudo, manipulação e classificação do corpo monstruoso. Tal fato se deu numa narrativa cultural hegemônica que passou a representar o corpo extraordinário nos termos clínicos da patologia médica.

\section{Emoções em jogo: horror ou empatia?}

Bill Nichols 33 afirma que as imagens "educam pela emoção" ao internalizarem valores morais muito complexos para serem expostos apenas em texto. A estética televisiva exclui o silêncio, o diálogo, a escuta, numa lógica de homogeneização da fala e do outro. A imagem torna-se asséptica, integrada, neutralizada. Aliás, o adjetivo de "educativo", nos vídeos analisados, merece, após todas essas reflexões, ser posto devidamente entre aspas. Eduardo Coutinho 34 , cineasta e documentarista brasileiro, faz o mesmo questionamento com relação à televisão em uma entrevista em que menciona o "real sem aspas". Coutinho 34 (p. 53) coloca: "O limite da televisão é o seu naturalismo. O repórter aparece para aprofundar a presença do 'real', que é um real entre aspas e que não é discutido".

O "educativo" nos vídeos analisados também não é discutido. Ao contrário, é legitimado pelo discurso "pedagógico", assemelhando-se a "aulas gravadas" ou a "reportagens". Talvez não seja por coincidência que a linguagem mais utilizada nestes vídeos seja a televisiva ou jornalística. Em um 
só tempo, tanto o discurso do "real" é legitimado pela estética jornalística, como o discurso do “educativo" pela estética do "pedagógico". Juntos, estes discursos complementam-se e legitimamse simultaneamente, tanto no conteúdo como na forma. Isso se dá de tal modo que na maioria dos vídeos abstrai-se a vida dos personagens, tornando-os meros casos clínicos, meras feridas, exibidas em close.

Esse tipo de exploração da imagem do outro, enquanto "doente", suscita questões de ordem ética: como trabalhar a imagem do outro sem tipificá-lo, sem estereotipá-lo, sem rotulá-lo e, sobretudo, sem subtrair-lhe sua identidade? Como não fazer do rosto do outro o rosto do típico, deixando com isso escapar a singularidade das forças e das paixões que o animam?

É preciso desconfiar da universalidade e da naturalidade dos traços expressivos que o rosto pode carregar. Deleuze \& Guattari 35 (p. 32) compreenderam bem o sistema de apropriação do rosto pelo cinema: o close pode tanto fazer com que o rosto reflita a luz quanto o contrário, “...mergulhá-lo na mais impiedosa obscuridade. (...) O close de cinema trata, antes de tudo, o rosto como uma paisagem. (...) O rosto não age aqui como individual, é a individuação que resulta da necessidade que haja rosto...”.

Arthur Omar 36 (p. 11) também opera questionamentos sobre o rosto afirmando que "o $\mathrm{mi}$ lagre do rosto é materializar esses mundos virtuais que refletem nos olhos, na expressão de cada personagem, esse é o sentido da Antropologia, um meticuloso trabalho de garimpo, registro e construção de um povo por vir ...".

Nos vídeos Diagnóstico Laboratorial (1995), Leishmaniose Tegumentar Americana e Leishmaniose Visceral (1983), percebe-se claramente aspectos do fascínio e do horror à carne. No primeiro vídeo, vemos a dissecação de um camundongo ao som de um jazz, fundo musical que se alterna com uma voz asséptica em off, de alguém que sabe, narrando um texto médico sobre os procedimentos ilustrados pela imagem. Em seguida, para o diagnóstico da leishmaniose visceral, vemos uma jovem negra num consultório, vestida com uma camisola hospitalar. Enquadrada em plano médio, ela se encontra de pé contra a parede e de frente para a objetiva da câmera. Esta jovem parece narrar alguns de seus sintomas, mas problemas técnicos de som impedem a compreensão do que ela diz. Um médico entra no quadro, abre a camisola da paciente, desnudando seu corpo, sobre o qual percebemos um desenho técnico, feito com hidrocor, representando o fígado e baço aumentado.

A jovem é totalmente desqualificada pela imagem enquanto sujeito, e se transforma em quadro negro sobre o qual o médico dá sua aula, percorrendo o desenho com o indicador. Esse recurso de desenhar com hidrocor o abdome dos portadores de leishmaniose visceral é comum na área médica, presente em abundância nos vídeos analisados e em manuais médicos e dermatológicos. Como na leishmaniose visceral os sintomas da doença se manifestam internamente, especificamente com inchaço do baço e fígado, médicos recorrem a esse recurso visual externo para representar os sintomas. Vê-se, mais uma vez, como a prática e saber médico são calcados na imagem. Como a leishmaniose visceral se manifesta internamente, trazem-se as imagens para "fora", sendo o corpo do portador o receptáculo das imagens médicas.

Le Breton 37 demonstra como o vínculo que formulamos com o corpo, na história moderna da medicina, se configura numa "síndrome de Frankenstein”. Conforme Le Breton 37 (p. 55): "Como os outros anatomistas, Frankenstein é fascinado pelos cadáveres e pela articulação complexa da carne; as incidências, a morte sobre o vivo suscita nele uma deliciosa curiosidade da qual ele não se cansa...".

Essa contaminação mútua de morte e vida, que ao mesmo tempo seduz e horroriza, está presente no imaginário da sociedade moderna. $\mathrm{O}$ grotesco é assim, quase sempre o resultado de um conflito entre cultura e corporalidade. Assim, Tomas Silva 38 (p. 20) nos lembra que "a pedagogia dos monstros recorre aos monstros para mostrar que o processo de formação da subjetividade é muito mais complicado do que nos fazem crer os pressupostos sobre o sujeito...".

Nos vídeos em geral, a informação, além de ser altamente técnica e receituária, não incorpora nenhum ou poucos fatores sociais relativos à doença, apoiada por uma forma desconectada da realidade. Faz-se tábula rasa da população. Ela é o recipiente onde os órgãos oficiais depositam suas informações e receitas do que fazer ou não. Esse é o enfoque de educação sanitária dominante nos serviços e materiais educativos de saúde. Stotz 30 define esse modelo como preventivo, abordando apenas fatores de riscos comportamentais e individuais. Assim, o apelo ao grotesco, horror, vitimização e "monstruosidade" dos doentes foram aspectos freqüentes nos materiais analisados.

Entretanto, a "monstruosidade e a impureza podem estar mais fundo que à flor da pele" 38 (p. 16). Conforme King (1981, apud Carroll 39; p. 280), ao se pensar sobre as implicações entre ideologia e horror: "A monstruosidade fascina porque apela para o republicano conservador de terno que há dentro de todos nós. Amamos e precisamos do conceito de monstruosidade porque é 
uma reafirmação da ordem pela qual todos nós seres humanos ansiamos. (...) Não é a aberração física ou mental em si que nos horroriza, mas, sim, a falta de ordem que essas situações parecem implicar. O criador de ficção de horror é, acima de tudo, também um agente da norma".

Um audiovisual que sai um pouco desse padrão estético dominante do grotesco é o vídeo da OMS intitulado Leishmaniasis: The Slow Killer (1990). Esse vídeo tem alguns aspectos positivos na forma de representar a doença. Apesar de o vídeo apresentar-se em estilo jornalístico, busca-se realizar uma crítica social da doença sem explorar imagens de miséria e sofrimento humano. Não se apela tanto para as questões grotescas da doença, com close em feridas, ou imagens do tipo. Se alerta para o fato de a doença ser crônica e degenerativa que, como afirma o próprio título, "mata lentamente". Neste vídeo percebeuse certo cuidado na construção da imagem do portador de leishmaniose, pois os aspectos de espetacularização da doença foram deixados de lado, enfatizando, a importância do tratamento e controle da doença.

\section{Discussão}

Brecht (1992, apud Bornheim 40) dá aportes teóricos importantes que podem contribuir para a construção de uma produção audiovisual que rompa com o modelo de vídeo educativo escravo da linguagem de televisão. Brecht rompe com a identificação e a catarse, que levam ou à empatia ou ao horror. O espectador descobre em si mesmo o espírito crítico, que nasce de certo estranhamento em relação ao tema representado. Esse distanciamento, produzido pela forma, é que garante a situação de aprendizagem. Nos vídeos analisados, o doente, representado como vítima, e o espectador, tido como agente passivo, é levado à empatia alienatória em relação à representação. Os sentimentos de horror e medo frente à doença o paralisam, impossibilitando a manifestação de qualquer espírito crítico necessário à aprendizagem. O doente é representado, ora como vítima, ora como causador da doença.

Assim, a análise dos vídeos demonstra como os materiais audiovisuais são potencializadores de percepções diversas, podendo reforçar representações estereotipadas e formas de dominação, em vez de contribuir com a educação em saúde. Ao focar e apelar às emoções, os vídeos analisados revelam um discurso que apela ao horror e à empatia, ambas inviabilizando formas construtivas de educação em saúde. Como Brecht (1992, apud Bornheim 40; p. 229), também nos perguntamos, "seria possível colocar, no lugar do horror o desejo de saber, e no lugar da compaixão, a solicitude?".

Acreditamos que sim. Há novas formas de representação das leishmanioses e do outro que podem auxiliar a educação a ser realmente pedagógica, onde o real e a educação se livram das aspas. Vemos essas possibilidades de novas abordagens estéticas e metodológicas, tanto no campo da antropologia da saúde como no da antropologia visual. Estas oferecem questionamentos produtivos e críticos da prática de representar o outro através de imagens.

Novas abordagens do "outro" no campo da saúde coletiva

Afinal, que tipo de sujeito é o outro? Sabemos o quanto a abordagem do outro parte equivocadamente da identidade do "mesmo", e o quanto é difícil reencontrar o outro por ele mesmo, para além de nossas projeções. De Flaherty, no início do século, a Eduardo Coutinho, passando, obrigatoriamente, por Jean Rouch, nos anos 50, a tradição do cinema antropológico mostra que é possível fazer das diferenças o ponto de partida para um documentário, permitindo que elas nasçam e se alimentem da interlocução, de tal modo que a alteridade seja produzida por essa negociação entre o filmante e o filmado. Ora, ao se referir ao "cinema vivido" do cineasta Pierre Perrault, Deleuze 41 (p. 183) afirma que o cinema deve apreender: “...não a identidade de um personagem, real ou fictícia, através de seus aspectos objetivos ou subjetivos. È o devir do personagem real quando ele próprio se põe a 'fabular', quando entra em 'flagrante delito de contar lendas'".

Resulta disso um novo estatuto da narração: a narração deixa de ser verídica, ou seja, aspirar à verdade, para se fazer essencialmente falsificante. "Há uma razão profunda para essa nova situação: contrariamente à forma do verdadeiro que é unificante e tende à identificação de um personagem (...) a potência do falso não é separável de uma irredutível multiplicidade. 'Eu é outro' substitui Eu = Eu" 41 (p. 163).

O documentário pode vir a estabelecer relações com esse novo estatuto da imagem. Vemos em Eduardo Coutinho uma abordagem igualmente interessante, que consiste num trabalho de resgate da vitalidade, da energia criadora dos tipos sociais apresentados. Em Coutinho, as pessoas que falam (ou cantam) não são mostradas como exemplos de nada. "Não são tipos psicosociais - o morador da favela ou o catador de lixo - não fazem parte de uma estatística, não justificam nem provam uma idéia central" 34 (p. 61).

A estética televisiva, ao contrário, obcecada pela informação e subjugada pelo tempo, não 
abre a possibilidade de admiração do outro, reduzindo sua singularidade ao típico, seu modo particular de vida ao "exemplar sociológico" 29. A edição em planos curtos e rápidos não abre espaço para uma escuta, muito menos, para um diálogo entre entrevistado e entrevistador.

No caso específico das leishmanioses, o apelo ao sentimento de horror é de especial perversidade, pois as lesões da leishmaniose tegumentar lembram muito as lesões desfigurantes da hanseníase. Ambas as doenças necessitam do mesmo tratamento com relação à imagem, pois preconceitos e representações estereotipadas, que remontam aos textos bíblicos, acabam sendo reforçados. Como ressalvam Sodré \& Paiva ${ }^{1}$ (p. 132), esta abordagem estética: "Permite encenar o povo e, ao mesmo tempo, mantê-lo à distância. Dão-se voz e imagem a energúmenos, ignorantes, ridículos, patéticos, violentados, disformes, aberrantes, para mostrar a crua realidade popular, sem que o choque daí advindo chegue às causas sociais, mas permaneça na superfície irrisória dos efeitos".

Os modelos hegemônicos de representação das doenças e do corpo no campo da educação em saúde parecem bastante desgastados. Vivemos talvez num momento de transição, em que parâmetros anteriores já não dão conta das redefinições de papéis que se configuram. Uma proposta de mudança de abordagem do audiovisual numa estrutura tão solidamente montada na prática institucional do campo da saúde é um trabalho complexo, que requer pesquisas de novas linguagens e vontade política para a introdução de abordagens diferenciadas, mais próximas do documentário antropológico do que da reportagem televisiva.

Novas abordagens estéticas e metodologias, tanto no campo da antropologia da saúde como no da antropologia visual, podem favorecer um questionamento produtivo da prática de se representar o outro através de imagens. Procura-se revelar a riqueza de elementos constitutivos da realidade social envolvida na forma de construção e utilização das imagens, onde as representações sobre saúde/doença moldam de forma marcante os dois extremos desta relação: usuários e prestadores de serviços.

Desta forma, explorar a interface entre materiais audiovisuais - vistos aqui como sistema cultural próprio - e a "população alvo", pode contribuir de maneira mais conseqüente no aprimoramento da atenção à saúde no Brasil. É de extrema importância encorajar o espírito crítico com relação aos materiais educativos, onde certos discursos e representações negativas e a-críticas em saúde podem apenas reproduzir ideologias, posturas e sistemas hegemônicos discursivos de nossa sociedade. As imagens podem ir muito além da simples transmissão da informação; pensar novos rumos pedagógicos e experimentais pode levar a uma ampliação do nosso horizonte teórico e metodológico, gerando uma verdadeira práxis do audiovisual e da imagem no campo da saúde coletiva. Deste modo, a práxis da produção audiovisual em saúde, como bem coloca o documentarista Eduardo Coutinho 34, deve se configurar como uma "cumplicidade com a vida". 


\section{Resumo}

Buscando compreender a produção de imagens sobre saúde e doença e seus efeitos de aprendizagem resultante da educação em saúde mediada pelos vídeos educativos, o artigo analisa a produção audiovisual sobre as leishmanioses no Brasil. Com base no estudo de 14 vídeos educativos, verificou-se a predominância de um discurso técnico-científico e uma estética do grotesco. Observou-se a hegemonia do modelo televisivo-espetacular, em particular o padrão do telejornalismo, com o uso constante de voz off, indutora da fixação de sentidos. Ao invés de estimular a reflexão crítica sobre as circunstâncias sociais do adoecimento, a prática discursiva e imagética dos vídeos encoraja a sua banalização, tanto pela abordagem pouco criteriosa da doença como pela construção de representações estereotipadas. Há a exposição visual de pessoas doentes e não o protagonismo crítico e sensível das populações implicadas. O artigo apresenta, então, com base nos estudos sobre a antropologia visual e da saúde, argumentos para uma abordagem inovadora na produção e utilização de vídeos educativos, e da educação em saúde mediada pelo audiovisual. Esta deve respeitar e dialogar com as culturas, a subjetividade e a cidadania, desenvolvendo estéticas audiovisuais (narrativas e imagéticas) como práxis educativa no campo da saúde coletiva.

Leishmaniose; Educação em Saúde; Antropologia

\section{Referências}

1. Sodré M, Paiva R. O império do grotesco. Rio de Janeiro: Editora Mauad; 2002.

2. Luz ZMP, Pimenta DN, Schall VT, Rabello A. Evaluation of informative materials on leishmaniasis distributed in Brazil: criteria and basis for the production and improvement of health education materials. Cad Saúde Pública 2003; 19:561-9.

3. Pimenta DN. As leishmanioses e suas representações: interação da linguagem do documentário com os saberes e práticas populares [Dissertação de Mestrado]. Rio de Janeiro: Núcleo de Tecnologia Educacional para a Saúde, Universidade Federal do Rio de Janeiro; 2003.

4. Pimenta DN, Leandro A, Schall VT. Experiências de desenvolvimento e avaliação de materiais educativos sobre saúde: abordagens sócio-históricas e contribuições da antropologia visual. In: Monteiro S, Vargas E, organizadores. Educação, comunicação e tecnologia educacional: interfaces com o campo da saúde. Rio de Janeiro: Editora Fiocruz; 2006. p. 87-112.

\section{Colaboradores}

D. N. Pimenta foi a responsável pela investigação, análise dos dados e redação final. A. Leandro contribuiu na análise das imagens. V. T. Schall contribuiu na revisão final do artigo e na análise dos vídeos educativos.

\section{Agradecimentos}

Estudo realizado com apoio do Conselho Nacional de Desenvolvimento Científico e Tecnológico (CNPq) e da Fundação de Amparo à Pesquisa do Rio de Janeiro (FAPERJ).

Agradecemos a Leonardo Barbosa Koerich pela revisão de texto.
5. Uchoa E, Barreto SM, Firmo JOA, Guerra HL, Pimenta FG, Costa MFFL. The control of Schistosomiasis in Brazil: an ethno-epidemiological study of the effectiveness of a community mobilization program for health education. Soc Sci Med 2000; 51:1529-41.

6. White K. The sociology of health and illness. Curr Sociol 1991; 39:1-123.

7. Maylysse S. Um ensaio de antropologia visual do corpo ou como pensar em imagens o corpo visto? In: Lyra B, Wilton G, organizadores. Corpo \& imagem. São Paulo: Editora Arte \& Ciência; 2002. p. 67-74.

8. Aumont J. A imagem. São Paulo: Editora Papirus; 1995.

9. Bernardet JC. Cineastas e imagens do povo. Rio de Janeiro: Editora Brasiliense; 1985.

10. Pinto PGHR. Saber ver: recursos visuais e formação médica. Physis (Rio J) 2000; 10:39-64.

11. Godard J-L. Jean-Luc Godard par Jean-Luc Godard. Cahiers du Cinema 1998; tome 2. 
12. Parente JI. Antropologia e cinema: questões de linguagem. In. Monte-Mór P, Parente JI, organizadores. Cinema e antropologia: horizontes e caminhos da antropologia visual. Rio de Janeiro: Editora Interior Produções; 1994. p. 41-56.

13. Piault MH. Real e ficção: onde está o problema? In: Kowy MGP, organizador. Imagem e memória: ensaios em antropologia visual. Rio de Janeiro: Editora Garamond; 2001. p. 13-186.

14. Samain E, Sôlha H. Antropologia visual, mito e tabu. Rio de Janeiro: Editora Museu do Índio; 1987. (Cadernos de Textos: Antropologia Visual).

15. Leroi-Gourhan A. Cinema et sciences humaines. Le film ethnologique existe-t-il? Revue de Géographie Humaine et d'Ethnologie 1948; 3:42-50.

16. Mead M. Visual anthropology in a discipline of words. In: Hockings P, editor. Principles of visual anthropology. Den Haag/Paris: Walter de Gruyter; 1975. p. 3-10

17. Artaud A. O teatro e seu duplo. São Paulo: Editora Martins Fontes; 1999.

18. Silva JR. Leishmaniose visceral (calazar) [Tese de Doutorado]. Rio de Janeiro: Serviço Nacional de Educação Sanitária; 1957.

19. World Health Organization. World Health Organization Expert Committee: control of the leishmaniasis. Geneva: World Health Organization; 1990. (WHO Technical Report Series, 793).

20. Luz ZMP, Pimenta DNP, Cabral ALL, Vianna ALL, Fiúza FOP, Rabello A. A urbanização das leishmanioses e a baixa resolutividade diagnóstica em municípios da Região Metropolitana de Belo Horizonte. Rev Soc Bras Med Trop 2001; 34:249-54.

21. Graham PCC. Introduction. In: Peters W, KillickKendrick R, editors. The leishmaniases in biology and medicine. Vol. I: biology and epidemiology. New York: Academic Press; 1987. p. 1-13.

22. Vanoye F, Goliot-Lété A. Ensaio sobre a análise fílmica. São Paulo: Editora Papirus; 1994.

23. Bakhtin M. A cultura popular na Idade Média e no Renascimento - o contexto de François Rabelais. São Paulo: Editora Hucitec; 1987.

24. Kayser W. O grotesco. São Paulo: Editora Perspectiva; 1986.

25. Hugo V. Do grotesco e do sublime. São Paulo: Editora Perspectiva; 1988.
26. Valla VV. A construção desigual do conhecimento e o controle social dos serviços públicos de educação e saúde. In: Valla V, Stotz E. organizadores. Participação popular, educação e saúde: teoria e prática. Rio de Janeiro: Relume-Dumará; 1993. p. 77-92.

27. Leandro A. Da imagem pedagógica à pedagogia da imagem. Comunicação e Educação 2001; 7:29-36.

28. Lins C. Imagens em metamorfose. Cinemais 1996; 1:45-56.

29. Schall V, Diniz MCP. Information and education in schistosomiasis control: an analysis of the situation in the state of Minas Gerais, Brazil. Mem Inst Oswaldo Cruz 2001; 96:35-43.

30. Stotz E. Enfoques sobre educação e Saúde. In: Valla V, Stotz E, organizadores. Participação popular, educação e saúde: teoria e prática. Rio de Janeiro: Relumé-Dumará; 1993. p. 11-22.

31. Rouch J. Áfricas, uma retrospectiva do potlatch: o dito cinema africano 1896-1996. In: Catálogo da 3a Mostra Internacional do Filme Etnográfico. Rio de Janeiro: Editora Interior Produções; 1996. p. 34-45.

32. Thonson RG. Freakery: cultural spectacles of the extrordinary body. New York: New York University Press; 1996.

33. Nichols B. Representing reality: issues and concepts in documentary. Bloomington/Indianápolis: Indiana University Press; 1991.

34. Coutinho E. A palavra que provoca a imagem e o vazio no quintal. Cinemais 2000; 22:31-72.

35. Deleuze G, Guattari F. Mille plateaux. Paris: Les Éditions de Minuit; 1980.

36. Omar A. Antropologia da face gloriosa. São Paulo: Cosac \& Naify; 1997.

37. Le Breton D. A síndrome de Frankenstein. In: Santana DB, organizador. Políticas do corpo. São Paulo: Editora Estação Liberdade; 1995. p. 49-67.

38. Carroll N. A filosofia do horror ou paradoxos do coração. Campinas: Editora Papirus; 1999.

39. Silva TT. A pedagogia dos monstros: os prazeres e perigos da confusão de fronteiras. Belo Horizonte: Editora Autêntica; 2000.

40. Bornheim G. Brecht: a estética do teatro. Rio de Janeiro: Editora Graal; 1992.

41. Deleuze G. Cinema 2: a imagem-tempo. São Paulo: Editora Brasiliense; 1990.

Recebido em 29/Ago/2005

Versão final reapresentada em 27/Out/2006

Aprovado em 30/Out/2006 